\title{
Kant:
}

\section{entusiasmo e revolução}

\author{
Ricardo R. Terra
}

“(...) esta Revolução, digo, encontra no espirito de todos espectadores (que não estão eles mesmos enredados neste jogo) uma simpatia de aspirações que beira o entusiasmo - cuja manifestação mesma seria perigosa - que não poderia ter outra causa senão uma disposição moral no gênero humano" Kant ${ }^{(1)}$

Em seu artigo sobre Fichte e a Revolução Francesa, Gueroult caracteriza da seguinte forma a recepção do processo revolucionário na Alemanha: "sabe-se com que entusiasmo foi recebida na Alemanha, pela elite intelectual, a notícia da Revolução. Conhecemos as causas. Havia nesse país o mesmo sistema feudal que na França e os mesmos abusos agravados pela falta de unidade, pelas circunstâncias locais, pela miséria do país esgotado pelas invasões sucessivas, a Guerra dos Sete Anos etc. A servidāo que quase desaparecera na França pesava ainda de maneira dura sobre o camponês alemão. O esforço de Frederico II e José II para reduzi-la tinha mais ou menos fracassado (...). Os estados estabeleciam contratos para a entrega reciproca de servos fugitivos. A opressão política e o arbítrio não tinham limites"(2). A situação variava um pouco nos diversos pequenos estados alemães, mas de qualquer forma não era nada animadora.

Não havia, entretanto, um movimento pré-revolucionário. O luteranismo político ainda era dominante, "o pensamento alemão fazendo sua a teoria de Lutero que, justificando o Estado pelo pecado, ordena a obediência incondicional ao Estado patriarcal e absoluto"(3) . A falta de unidade política e a fragmentação em muitos pequenos principados dificultavam qualquer articulação nacional, e o "atraso" relativo da Alemanha enfraquecia a burguesia, carente de iniciativa, assumindo o Estado um peso maior que nos outros países, tanto nos negócios como na vida social. Em meio a essa situação, não é de estranhar a passividade dos súditos, à espera de que as mudanças sociais e econômicas fossem de iniciativa do monarca.

Diante deste quadro, os intelectuais alemães, à época da Revolução Francesa, tendem ao apoliticismo, na medida em que identificam a política com os interesses mesquinhos dos pequenos territórios ${ }^{(4)}$. Mas o interessante é que se tornará uma característica da inteligência alemã a coexistência de uma visão limitada com o universalismo. Como assinalaram Marx e Engels em relação aos burgueses alemães explorados pelos burgueses de outros países - e que estando presos aos interesses locais não conseguiam encarnar os interesses nacionais - "a estes mesquinhos interesses locais correspondia de um lado a limitação local e provinciana de fato do burguês alemão, de outro lado sua presunção cosmopolita"(5). Os burgueses alemães e os espíritos cultivados aceitavam o particularismo e o absolutismo dos pequenos príncipes e sonhavam com o cosmopolitismo. Será nesse contexto que se dará a recepção alemã da Revolução Francesa. Como os intelectuais não tinham experiência política, era-lhes difícil perceber a real dimensão política dos acontecimentos, não conseguiam equacionar a dimensão histórica da Revolução. Ela aparecia como um fato metafísico e, quando os alemães encararam os princípios da liberdade e igualdade, foi no plano ético e não no da política efetiva ${ }^{(6)}$.

De qualquer maneira, apesar de não ter durado muito - pois eles recuaram medrosamente diante das primeiras notícias da radicalização do processo revolucionário e do Terror -, houve um certo entusiasmo dos intelectuais alemães pela Revolução Francesa.
RICARDO RIBEIRO TERRA é professor de História da Filosofia e Filosofia Política do Departamento de Filosofia da FFLCH da USP e organizador do volume de Kant "Idéia de uma história universal de um ponto de vista cosmopolita" (Brasiliense).

(1) Uma primeira versão deste texto foi apresentada na mesa-redonda: "Kant, Fichte e a Revolução Francesa", no Coloquio: "1789 Sombras e Luzes", promovido pela ANPOF, em outubro de 1987. Com esta comunicaçăo, pretende-se apenas fazer uma revisão das principais referências de Kant à Revoúc me de alguns comentadores. Os trabalhos básicos sobre Kant e a Revoluçāo Francesa, que usarei livremente e de maneira breve, são os de: Vorländer, K. "Kants Stellung zur Französische Revolution" in Philosophische Abhandlugen $\mathrm{H}$. Cohen zum 70 sten Geburtstag 14. Juli 1912 dargebracht, Berlin, 1912. Schrecker, P. "Kant et la Révolution Française" in Revue philosophique de la France et de I' étranger $n^{\circ}$ 9, 1939. Beck, L.W. "Kant and the right of Revolution" in Journal of the History of ldeas. 32 . Jg. 1971. Burg, P. Kant und die Französische Revolution. Berlin, Duncker \& Humblot, 1974. Fetscher, I. "I. Kant und die Französische Revolution" (1974) in Materialien Kants Rechtsphilosophie. Frankfurt, Suhrkamp, 1976. O melhor estudo geral; parece, continua a ser o de Droz, J. L'Allemagne et la Révolution Française. Paris, PUF, 1949.

(2) Gueroult, M. "Fichte et la Révolution Française" in Etudes sur Fichte. Paris, Aubier-Montaigne, 1974, p. 156.

(3) Droz op. cit., p. 9.

(4) Ver Droz, idem, p. 27.

(5) Marx e Engels. Die deutsche Ideologie. M.E.W., 3, 177.

(6) Ver Droz, p. 27 
A posição de Kant só em parte acompanha a da intelectualidade alemã. Várias anedotas são repetidas pelos biógrafos. Kant teria mudado o velho hábito de seus passeios, para ir ao correio em busca de notícias dos acontecimentos franceses. Seria chamado de jacobino, e mais ainda, houve um boato em Königsberg que sugeria ter sido Kant convidado a ser o legislador da França. Kant se destaca dos outros pensadores de sua época à medida em que, ao lado da crítica aos crimes da Revolução, ele continua seu defensor até o fim da vida.

\section{I - Filosofia político-jurídica e Revolução Francesa}

Pretendo, neste texto, apenas examinar as reações de Kant à Revolução e não fazer uma análise da concepção político-jurídica de Kant e compará-la com a Constituição francesa ou aproximá-la dos escritos dos revolucionários.

Um erro corrente é o de se pensar que Kant começou a interessar-se pela política e pelo direito político apenas a partir desta época. Schrecker, por exemplo, escreve: "pode-se adiantar que foi a experiência francesa que despertou em Kant o espírito político e dirigiu seu pensamento para os problemas filosóficos colocados pela organização social da humanidade, problemas que, antes de 1789, não se encontrará traços notáveis em sua obra" (7). Na verdade Kant não publicou textos importantes sobre o tema antes de 1789 (com exceção da Idéia de uma história universal de um ponto de vista cosmopolita, que é de 1784). Mas o pensamento político-jurídico de Kant já estava se formando há muito tempo. Há um grande conjunto de notas sobre o direito nos inéditos kantianos. Alguns comentadores procuraram ordenar este material e datá-lo. Daí surgiu, inclusive, a questão de se há ou não uma teoria do direito pré-crítica e uma outra crítica. Certos autores defendem a posição que não houve mudança - não haveria uma teoria do direito propriamente crítica. Para outros a fase crítica se formaria na década de 1770 ou de 1780, de qualquer forma antes da Revolução(8).

(7) Schrecker, p. op. cit., 394.

(8) Ver os livros de: Ritter, C. Der Re chtsgedanke Kants nach den frühen Quellen. Frankfurt, V. Klostermann, 1971. Busch, W. Die Entstehung der kritischen Rechtsphilosophie Kants. Berlin, W. de Gruyter, 1979. Sänger, M. Die kategoriale Systematik in den Metaphysischen Anfangsgründen der Rechtslehre. Berlin, W. de Gruyter 1982. Kersting, W. Wohlgeordenete Freiheit. Berlin, W. de Gruyter, 1984.

(9) Gueroult, M. op. cit. p. 168. Philonenko segue esta interpretação, por
exemplo, na página 60 de Théorie et Praxis dans la pensée morale et politique de Kant et de Fichte en 1793. Paris, Vrin, 1968.

(10) Nas próximas páginas, será apre sentado um resumo de um aspecto
da análise de Burg. A divisáo dos períodos da revolução encontra-se nas páginas 19 e 20.

(11) As obras de Kant săo citadas segundo a edição da Academia (Kants gesammelte Schriften. Herausgegeben von der Königlich Preussischen ben von der Königlich Preussischen indicaçōes entre parênteses obedecem à seguinte ordem: abreviatura da obra, algarismo romano indina. Abreviaturas das obras de na. Abreviaturas das obras de Kant: K.U. - Kritik der Urteilskraft. Auf. Beantwortung der Frage: Was is Aufklärung? Theor. Prax. - Übe den Gemeinspruch: das mag in der Theorie richtig sein, taugt aber nicht für die Praxis. Z. ew. Fried. - Zum ewigen Frieden. Rechtsl. - Metaphysik der Sitten. Rechtslehre. Streit - Der Streit der Fakultäten. Rel. - Die Religion innerhalb de Grenzen der blopssen vernunft. Grundl. - Grundlegung zur Metaphysik der Sitten. Trad. P. Quintela. Os Pensadores. Abril Cultural, 1980. Anthr. - Anthropologie in pragmatischer Hinsicht.
Os fundamentos da concepção político-jurídica kantiana já estavam formados na épo-
ca da Revolução Francesa. Ocorreram algumas mudanças, é claro, nas obras escritas e publicadas na década de 1790. Inclusive, não se pode comparar a articulação de notas com a articulação de livros. Mas além dos acontecimentos políticos, a polêmica intelectual também conta na articulação da doutrina político-jurídica kantiana.

De qualquer forma, o interesse kantiano pela política, pela organização da sociedade, é anterior à Revolução. Não se pode esquecer suas leituras de Rousseau, seus cursos de Direito Natural e o interesse pela independência americana. A quase ausência de publicaçōes anteriores à década de 1790 pode ser explicada pela urgência da obra crítica. A Terceira Crítica só é publicada em 1790. O entusiasmo kantiano é mais forte justamente por ele encontrar no processo revolucionário elementos que vão no mesmo sentido de seu pensamento.

\section{II - Avaliação favorável ou contrária à Revolução Francesa}

Podemos agora enfrentar a questão da avaliação feita por Kant da Revolução Francesa. Quanto à avaliação positiva inicial, não há nenhuma dúvida. A questão surge com a execução do rei e o período do Terror. Teria Kant seguido a intelectualidade alemã e condenado a Revolução, ou apenas condenado os crimes cometidos, mantendo sua avaliação positiva em relação ao processo revolucionário?

Gueroult, em seu já citado artigo, afirma: "Kant aprovará a Revolução Francesa enquanto ela parecer ser conduzida pelo rei, e a desaprovará quando se voltar contra ele. Kant verá em suas violências a prova de uma insuficiente preparação dos espíritos e das vontades e também é o penhor da anarquia, pois a idéia de uma resistência ao chefe do Estado é contrária ao princípio fundamental de toda constituição civil e conseqüentemente ao comando imperioso da razão prática"(9). Neste texto, aparecem várias questões que trataremos por partes, deixando o direito de resistência para mais tarde. Será que a condenação do rei levou Kant a desaprovar a Revolução ou apenas condena Kant o processo injusto?

Vejamos alguns textos de Kant e a ordenação proposta por Peter Burg em Kant und die Französische Revolution. A tese geral deste livro é que Kant faz um juízo geral positivo da Revolução, e negativo em relação a vários acontecimentos e mesmo períodos ${ }^{(10)}$.

\section{1ํ Período - Monarquia constitucional (1789-1792) - avaliação positiva.}

Nos textos editados, a primeira referência estaria no parágrafo 65 da Crítica do Juizo (11): "por ocasião da transformação completa, recentemente realizada, de um grande povo em um Estado, se serviu freçüentemente do termo organização de uma maneira muito apropriada pa- 


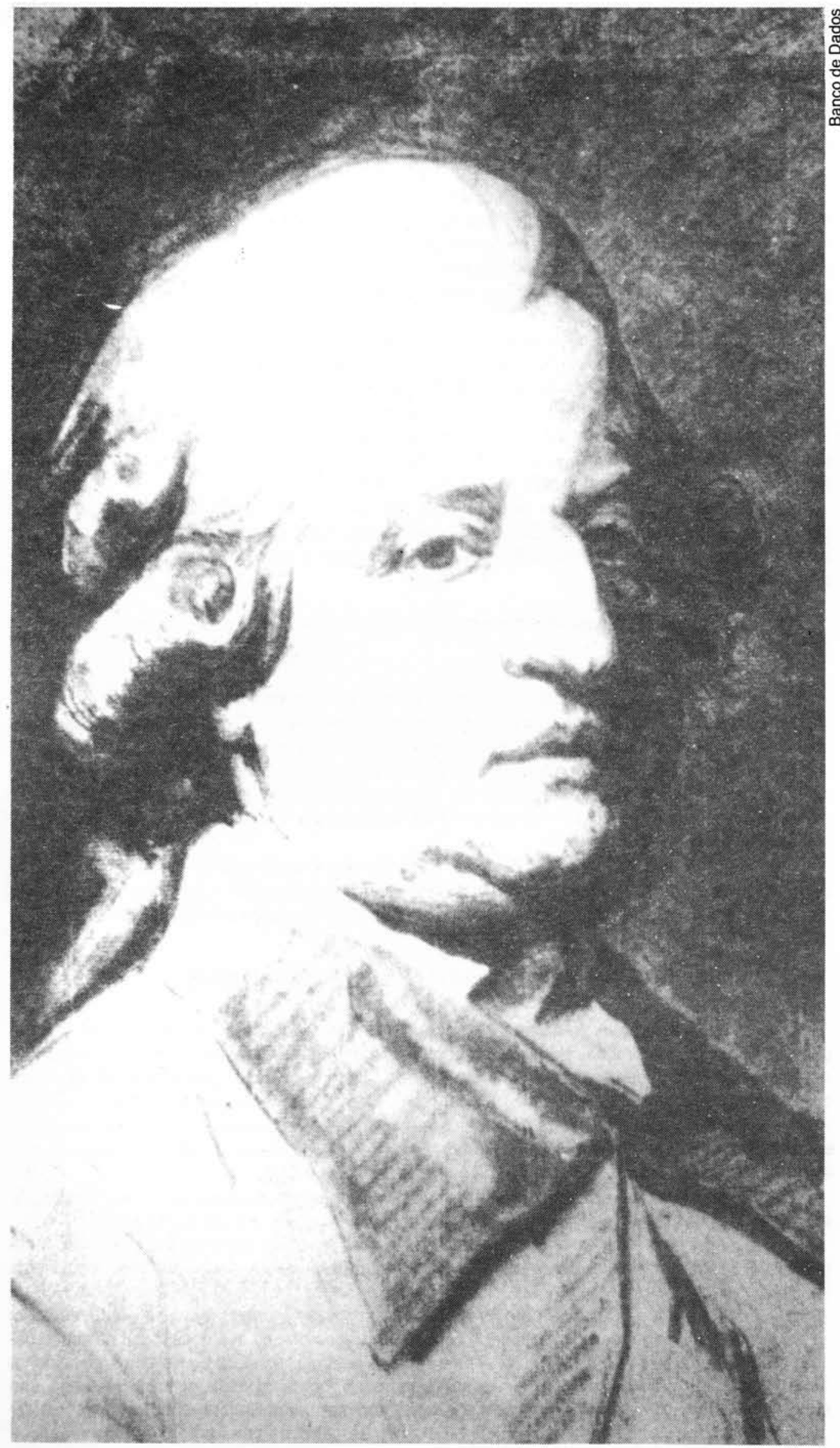

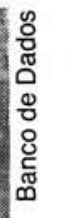

Luis XVI, rei da França de 1774 a 1792 
ra a instituição da magistratura ... etc., e mesmo do corpo inteiro do Estado. Pois cada membro deve certamente em um tal todo ser não apenas meio, mas ao mesmo tempo fim e, enquanto colabora para a possibilidade do todo deve por sua vez, no que concerne seu lugar e sua função, ser determinado pela idéia do todo"(12). Kant retoma aqui uma das formulaçōes do imperativo categórico: "Age de tal maneira que uses a humanidade, tanto na tua pessoa como na pessoa de qualquer outro, sempre e simultaneamente como fim e nunca simplesmente como meio" (Grundl. IV, 429, Trad. p. 135). Há uma ampliação do imperativo para o direito político. A idéia do todo serve de referência para todos os membros e também para a relação dos membros entre si. Vorländer ressalta a importância desta passagem da K.U.: "Temos, pois, diante de nós, nesta passagem tão significativa, um dos mais importantes aperfeiçoamentos da ética aplicada de Kant. Se se pode falar que até então toda tendência social em última análise mostrou-se uma tendência individual, porque a forma do imperativo categórico apenas se dirige para o indivíduo, vêmo-lo aqui se ampliar para a ética social, porque relacionado ao todo, ou, dito de outra maneira, ampliar-se para uma política no mais alto sentido da palavra"(13).

$\mathrm{Na}$ Rechtslehre, a tomada do poder pela assembléia nacional é vista como iegal (voltaremos a esta questão mais tarde). Na segunda edição da Rechtslehre, Kant abre a possibilidade do Estado secularizar os bens da Igreja católica, faz uma referência à República francesa e escreve adiante: "com efeito, a Igreja ela mesma é apenas uma instituição simplesmente fundada na fé e quando pelo desenvolvimento das luzes no povo a ilusão nascida desta opinião desaparece, e desmorona a temível potência do clero que se fundava nela, o Estado se apropria com pleno direito da propriedade que se atribuía à Igreja" (Ak. UI, 368/369).

Nesta passagem, fica claro como a concordância de Kant com a Revolução não se dá apenas em função da concepção geral da constituição republicana e da constituição que poderia levar à paz, mas diz respeito também a aspectos particularmente polêmicos, contra os privilégios da Igreja e da nobreza.

2 Periodo - República democrática (1792-1794) - o juizo sobre os acontecimentos é negativo.

A condenação de Luís XVI é reprovada com veemência na Rechtslehre (VI, 320 e ss.). $O$ assassinato de um monarca pode ser explicado pelo medo. $O$ povo se protege assim da possível retomada do poder pelo monarca e as consequeências repressivas provenientes daí. Pior que o assassinato é o julgamento do rei, o que vai contra todos os direitos, pois se o rei não é mais o soberano, ele não pode ser julgado por sua administração passada, quando era o soberano - a soberania é inatacável. Kant compara o crime da execução a um pecado mortal que não pode ser absolvido nem no outro mundo.

Na Anthropologie (VI, \#77, 259), o comitê de salvação pública é condenado: "no decorrer de uma situação revolucionária (eines revolutionären Zustandes) a ilegalidade pública é declarada legítima (por exemplo, na época do comitê de salvação pública da República Francesa)".

$$
\text { 3ํoríodo - República burguesa (1794-1799) - avaliação positiva. }
$$

No Streit, no início da terceira seção - conflito da faculdade de filosofia com a faculdade de medicina -, comentando a maneira de tratar moralmente o físico do homem, Kant compara o médico à convenção francesa, que não apenas emprega os meios oferecidos pela experiência e ordenados pela razão, mas sabe ordenar o que é ao mesmo tempo dever (Streit, VII, 97/98).

Há algumas Reflexões do período que avaliam positivamente a convenção ( $R \times 1077)$, e também um comentário de 1798/1799 sobre a atuação de Napoleão no Egito, onde toma partido da França (Ak. XII, 381).

As biografias e relatos escritos enquanto Kant ainda vivia testemunham o interesse e

(12) K.U.V., \#5, 375. Hannah Arendt em Lectures on Kants Political Philosophy, The University of Chicago Press, 1982, p. 16,10 esta passagem, ao contrário de todos os outros comentadores, como se referindo a Revoluçăo Americana. Ela ressalta a transformaçăo de um povo em um Estado, os outros ressaltam o "recentemente".

(13) Vorlănder, K. op. cit., p. 252.

(14) Ver Burg op. cit., p. 28/29. a posição favorável à Revolução nestes anos em que Kant ainda expressa sua opinião ${ }^{(14)}$.
Antes de analisar as dificuldades da posição kantiana, gostaria de citar uma passagem de 1793, de um livro reeditado em 1794, que mostra a defesa kantiana da Revolução. Neste texto, Kant não apenas defende a Revolução, mas de certo modo justifica seus enganos (Rel. VI, 188). "Reconheço que não pode parecer-me boa a expressão que pessoas inteligentes também utilizam: um certo povo (que está ocupado com a elaboração de sua liberdade legal) não está maduro para a liberdade (...). Segundo um tal pressuposto nunca a liberdade se realizará, pois não se pode amadurecer para esta se antes não se foi posto em liberdade" (Rel. VI, 188). Segue-se uma frase significativa: "Os primeiros ensaios serão certamente rudes, ligados, em geral, a uma situação mais incômoda e perigosa que aquela de quando se estava sob as ordens mas também cui- 
dados de outrem, entretanto só se amadurece para a razão através dos ensaios próprios (que para poderem realizar-se exigem que se seja livre)" (idem).

Mesmo que os textos de Kant não sejam muitos para uma descrição pormenorizada de suas reações aos diversos desdobramentos da Revolução, podemos constatar um contínuo interesse e, mais, ainda uma avaliação geral positiva, principalmente se levarmos em conta o Streit der Fakultäten, que é de 1798.

É importante ressaltar não apenas que o processo revolucionário tem várias fases, e Kant vai julgando-as, como também convém insistir que seu ponto de vista não é o mesmo em to-

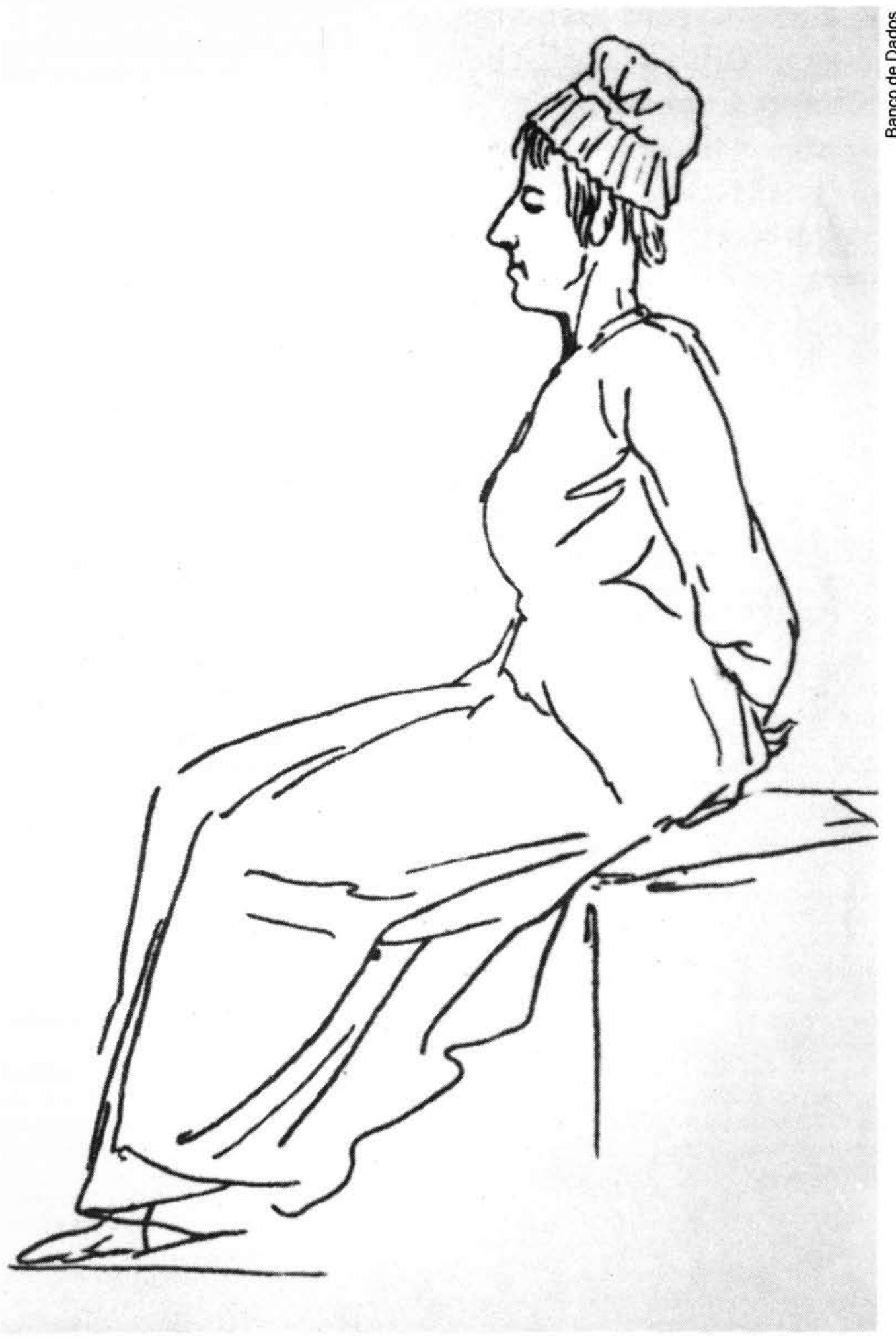


dos os textos. Em alguns, o juízo é político-jurídico e em outros político-histórico (diz respeito à filosofia da história). Vejamos os dois separadamente.

\section{III - Direito de resistência}

Uma grande dificuldade para se pensar a Revolução Francesa no plano do direito é a negação categórica, por Kant, de qualquer direito de resistência. $\mathrm{O}$ direito de resistência está intimamente vinculado à noção de soberania.

Vários autores se ocuparam da questão da soberania em Kant, constituindo-se uma interessante polêmica a respeito. Vamos seguir aqui, mais uma vez, Peter Burg, quando distingue na filosofia política kantiana três concepçōes da soberania:

I - Concepção do direito natural. O povo é soberano, participa da legislação. "O construtor e detentor do poder estatal são idênticos: a vontade geral unida do Povo". Na terminologia contemporânea, corresponderia a uma concepção democrática da soberania.

II - Concepção de compromisso. Mantém a concepção do direito natural, mas constrói uma ponte com as formas estatais históricas. Seria possivel governar segundo o espírito da soberania popular e dominar de maneira autocrática. Dar-se-ia uma ligação do soberano com a vontade do povo na medida em que esta pudesse servir de diretriz para ele. Poderia ser chamada aufgeklärt absolutistiche Souveränitätskonzeption.

III - Concepção absolutista da soberania. A terceira concepção seria encontrada na nota geral entre os parágrafos 49 e 50 da Rechtsl., e tem como ponto de partida o modelo do pacto de sujeição. A vontade do povo, neste caso, não é tomada em consideração, diferentemente do que ocorre na segunda concepção, onde é levada em conta, embora indiretamente. Por causa dessa independência do soberano em relação ao povo, pode-se falar de uma concepcão absolutista da soberania, cuja validade fatual não é apenas constatada mas também aceita ${ }^{(15)}$.

A soberania na terceira concepção é de tal forma absorvida pela pessoa do governante que até mesmo a referência ao povo através da representação acaba desaparecendo. Isto acontece nos textos em que Kant trata da impossibilidade do direito de resistência, tanto na Theor. Prax. e Z. ew. Fried. quanto na Rechtsl.. O povo não pode se rebelar, pois "vê-se facilmente que, se se quer colocar como condição, na instituição de uma constituição política, que a força possa ser usada em certos casos contra o soberano (Oberhaupt), o povo deveria arrogar-se um poder legítimo sobre este. Então, este não seria o soberano" (Z. ew. Fried. VIII, 382). Ora, o povo não é o soberano, não detém o poder supremo. A rebelião destruiria o Estado legal, pois "cada membro do corpo comum tem um direito de coerção em relação a todos os outros, com exceção apenas do próprio soberano (Oberhaupt) (porque ele não é membro deste corpo, mas seu criador ou conservador), apenas tem a competência de coagir, sem ser ele mesmo submetido a uma lei de coerção" (Z. ew. Fried. VIII, 291). O soberano-chefe do Estado, como criador ou conservador do Estado, está fora de qualquer coerção. Logo, sua destruição numa revolta seria a destruição do próprio Estado civil e a volta ao Estado de natureza.

Não há nenhum espaço para o direito de resistência. No próprio direito positivo, ele seria desprovido de sentido, pois "que a constituição contenha uma lei que autorizaria derrubar a constituição existente, de onde decorrem todas as leis particulares (...), é uma clara contradição" (Theor. Prax., VIII, 303).

Do confronto do direito natural com o direito positivo, também não se pode fundar o direito de resistência, pois "uma constituição jurídica qualquer, mesmo em um pequeno grau conforme ao direito, é melhor do que nenhuma constituição, a cujo destino (a anarquia) uma reforma precipitada levaria" (Z. ew. Fried., VIII, 373). Chegamos à fórmula da Rechtslehre: "deve-se obedecer ao poder legislativo existente qualquer que possa ser sua origem" (Rechtsl. VI, 319).

Um outro aspecto da questão do direito de resistência é a publicidade. No segundo apêndice de Zum ewigen Frieden, Kant acrescenta mais um argumento contra o direito de resistência - a forma da publicidade como pedra de toque da justiça das ações. Os revoltosos não podem tornar públicos seus propósitos, já o governante pode tornar pública a intenção de punir qualquer sublevação.

Resta aos súditos a liberdade de escrever "com o favor do soberano (Vergunstimim, em "O idealismo polftico kanlosofia da Ciência, 5/1983, p. 53.

(16) Ver Auf. e Habermas Strukturwandel der Öffentlichkeit. Neuwied e Berlin, Luchterhand, 1974.\#13 Publizität als Prinzip der Vermittlung von Politik und Mortal (Kant). Trad. Mudança estrutural da esfera pública. Rio de Janeiro, Tempo Brasileiro, 1984. gung)" (Theor. Prax. VIII, 304); "como único paládio dos direitos do povo" (idem). Mesmo assim no plano do uso público da razão(16).

O âmbito da liberdade é o uso público e por escrito, o que, na leitura de Habermas, remete para o mundo dos alfabetizados e em última instância ao público que tem de alguma maneira um tipo de independência financeira, ou seja, o cidadão ativo. Kant, como a Constituição de 
1791, distingue o cidadão ativo do passivo, e apenas os primeiros podiam votar. Os domésticos: por exemplo, por não terem independência eram considerados cidadãos passivos e não tinham o direito de $\operatorname{votar}^{(17)}$.

As mudanças têm que vir de cima para baixo. O soberano conduz as reformas necessárias no momento oportuno. Mas mesmo o soberano só pode mudar a forma de governo e não a forma de soberania, a forma de império, ou seja, ele pode modificar a forma de governo, passando do despotismo para a república, mas não a forma de soberania, a transformação de uma monarquia em democracia ${ }^{(18)}$.

\section{IV - Legitimidade ou ilegitimidade da Revolução}

Qualquer revolução é ilegal e ilegítima, mas a constituição proveniente dela deve ser obedecida. Pois é uma obrigação seguir o poder estabelecido. Tanto na $Z$. ew. Fried. como na Rechtsl., Kant insiste em que a ilegalidade do começo não atinge a legalidade atual. Isto vale tanto para a origem de qualquer poder estatal como também para as revoluções. Quando Kant escreve: "mesmo se pelo impeto uma revolução, provocada por uma má constituição, conquistou de maneira ilegal uma constituição conforme à lei, não será permitido depois conduzir o povo para a antiga" (Z. ew. Fried.), ele está defendendo os direitos da revolução contra a restauração.

Não se resolveu ainda a questão da legitimidade do início da Revolução. No fim do parágrafo 52 da Rechtsl., Kant afirma que foi um erro de avaliação de Luís XVI convocar os estadosgerais, pois assim os poderes soberanos do monarca desapareceram completamente, passando para o povo.

Vários comentadores, desde Vorländer a Schrecker ou Fetscher, vêem aí a solução não houve revolução e sim reforma, iniciada pelo monarca.

A solução mais curiosa é a de Dieter Henrich - quando conclui que não é possivel uma mudança legítima da forma de soberania, pois, "se um monarca proclama a república ou um parlamento derruba um tirano - tem-se do mesmo modo injustiça"(19). A solução kantiana seria surpreendente, a Revolução não foi uma revolução, neste ponto Henrich segue outros estudiosos de Kant, mas o mais interessante é que como o soberano não pode mudar a forma do regime, quando o soberano-monarca convocou a Assembléia, passou o poder para ela e assim se tornou o único revolucionário de $1789^{(20)}$.

\section{V - Ponto de vista da história}

Contra Henrich, que resolve um paradoxo com outro maior ainda, White Beck ${ }^{(21)}$ propõe que se mude de ponto de vista, que se passe do ponto de vista jurídico para o da filosofia da história. O progresso é julgado pela liberdade política. Outros autores também vão por esta via. Em uma perspectiva da filosofia da história, pode-se pensar na evolução das constituições, na formação da liberdade. No Streit, a Revolução Francesa será vista como sinal do progresso. $\mathrm{Na}$ verdade, não tanto a Revolução, mas o entusiasmo que ela provoca nos espectadores.

No plano da história, que tem como motor o conflito, pode-se entender também os crimes da Revolução. A tendência geral vai no sentido da Constituição republicana, mas é possível construir um estado mesmo com um povo formado por demônios.

De qualquer forma, esta perspectiva histórica não justifica, no plano do direito, a Revolução. Há no pensamento político-jurídico kantiano uma grande tensão entre a manutenção da ordem e a exigência do Estado de direito.

Um outro plano de abordagem da questão é aquele do entusiasmado espectador alemão que Kant descreve no Streit. O sinal da moralidade estaria nesta adesão desinteressada. Como nota Hannah Arendt, o espectador é aqui privilegiado em relação aos aiores. O entusiasmo é o sinal da moralidade e nos leva a afirmar o progresso. Kant abre neste texto uma importante perspectiva de reflexão política, a política pensada não apenas nos parâmetros do direito, mas em um juízo reflexionante. A ação política não é pensada apenas no plano de seu acordo com os princípios universais do direito racional. $O$ singular é pensado sem uma regra prévia como em um juízo estético, onde há um acordo das faculdades e não a legislação da razão ou do entendimento. Temos também que aprender na Kritik der Urteilskraft como pensar a política. (Acredito que $\mathrm{H}$. Arendt e também Lyotard ${ }^{(22)}$ ressaltam esta perspectiva, mas, não levando em conta devidamente a Rechtslehre, são parciais em suas leituras).

Por outro lado, reforçando a perspectiva do espectador, Kant entra de alguma maneira no quadro analisado por Droz: "esvaziada de sua substância histórica, a revolução aparecerá à inteligência alemã como um fato metafísico de que ela calcula o valor ético" (23) (Droz p. 27).
(17) Ver de Kant: RechtsI. VI, \#46 e Theor. Prax. VIII, 295. Na Constituiçăo francesa de 1791 , apenas os cidadãos ativos vintam e podem ser votados. Para ser cidadão ativo, é preciso, entre outras condiçōes, ser francês, ou tornar-se francês, ter 25 anos, "payer dans un lieu quelconque di royaume une contribution directe ou moins égale à la valeur de trois journées de travail et en répresenter la quittance, $n$ ' être pas dans un er lat de domesticite. dire de serviteur à gages." Seção II, Art. 2 in Franz, G. Staatsverfassungen. Darmstadt, 1975, p. 316.

(18) Ver Rechtsl. \#2 e Terra, R.R. "A constituiçăo como idéia e desígnio histórico em Kant" in Fortes, L.R.S. e Nascimento, M.M. (org.) A constituinte em debate. Sofia Editora, 1982

(19) Henrich, D. "Uber den Sinn vernünttigen Handelns im Staat" in Kant, Gentz, Rehberg Über Theorie und Praxis. Frankfurt, Suhrkamp, 1967, p. 29.

(20) Idem, p. 32.

(21) Op. cit., 417.

(22) Lyotard, J.F. L' Enthousiasme. La critique kantienne de I' histoire. $\mathrm{Pa}$ ris, Galilée, 1986.

(23) Op. cit., p. 27 